\title{
Varis dışı üst gastrointestinal sistem kanamaları: Son 25 yılda ne değişti?
}

\section{Nonvariceal upper gastrointestinal system bleeding: What has changed in the last 25 years?}

\author{
(D) Muhammed KAYA ${ }^{1}$, (D) Züleyha AKKAN ÇETINKAYA², (D) Gökhan DINDAR ${ }^{3}$, (D) Umut POLAT², \\ (D) Murat ÖZTÜRKLER ${ }^{3}$, (D) Mesut SEZIKLI ${ }^{3}$ \\ Sağllk Bilimleri Üniversitesi Kocaeli Derince Eğitim ve Araştırma Hastanesi ${ }^{1}$ Iç Hastalılan Kliniği, ${ }^{3}$ Gastroenteroloji Kliniği, Derince, Kocaeli \\ Bahçeşehir Üniversitesi Tip Fakültesi, ${ }^{2}$ Gastroenteroloji Bilim Dall, Istanbul
}

\begin{abstract}
Giriş ve Amaç: Çalışmamızda kliniğimizde son 1 yılda varis dışı üst gastrointestinal sistem kanaması tanısıyla özofagogastroduodenoskopi yapılan vakaların incelenmesi, 1993 ve 2008 yılındaki verilerle karşılaştırılması amaçlanmıştır. Gereç ve Yöntem: S.B.Ü. Derince Eğitim ve Araştırma Hastanesi Gastroenteroloji Kliniǧi'nde son 1 yılda varis dışı üst gastrointestinal sistem kanama tanısıyla özofagogastroduodenoskopi yapılan tüm hastalar, retrospektif olarak taranmıştır. Tespit edilen toplam 160 hastanın demografik verileri, komorbiditeleri ve özofagogastroduodenoskopi sonuçları analiz edilmiştir. Elde edilen sonuçlar aynı bölgede elde edilen 1993 ve 2008 verileri ile karşılaştırılmıştır. Bulgular: Erkek kadın oranı 2:1, ortalama yaş 59.8'dir. En sik gastritler, ikinci olarak peptik ülser saptanmıştır. Ülserler en sık bulbusta görülmüstür. Bulbus ülserlerinde antruma göre aktif kanama bulguları daha sıktır. 1993 ve 2008 verilerine göre yaş ortalaması ve kadınların oranı artış göstermektedir. Duodenal ve gastrik ülserler anlamlı ölçüde azalırken gastritlerin oranı artmaktadır. Sonuç: Varis dışı üst gastrointestinal sistem kanamaları erkeklerde ve ileri yașta daha fazladır. Son 25 yılda artan yaşam süresi ve Helicobacter pylori tedavi başarısındaki artışa bağlı olarak hastaların ortalama yașları artmakta, ülser sıklığı azalmaktadır. Güncel tedavi yaklaşımları sayesinde gastrointestinal sistem kanamalarına bağlı mortalite oranlarn azaltilabilir.
\end{abstract}

Anahtar kelimeler: Gastrointestinal sistem kanaması, endoskopi, varis dışı kanama

\section{GİRISS}

Üst gastrointestinal sistem (GIS) kanamaları gastroenterolojik aciller içerisinde en sık görülenlerden olup çoğu zaman acil müdahale ve takip gerektiren olgular olarak değerlendirilmektedir. Bu hastaların önemli bir kısmında hospitalizasyon ihtiyacı olmakta, yoğun sıvı tedavisi, asit baskılayıcı ajanlarla tedavi ve gerektiğinde kan transfüzyonu yapılmaktadır. Bütün tedavilere rağmen mortalitesi \%5-14 arasında seyretmektedir $(1,2)$. Dünyada olduğu gibi ülkemizde de hastaneye yatış gerektiren yaygın nedenlerden biridir. Özofagogastroduodenoskopi (ÖGD) üst GIS kanamalarının tanı ve tedavisinde altın standart olup rekürren kanamaları ve mortaliteyi azaltmaktadır (3). Bizim kliniğimize de çok sayıda üst GIS kanaması olgusu başvurmakta olup bu çalışmamızda, son 1 yılda kliniğimizde özofagus varis dışı üst GIS kanama ön tanısıyla acil endoskopi yapılan vakaların özelliklerini incelemeyi
Background and Aims: In our study, we aimed to investigate patients with nonvariceal upper gastrointestinal system bleeding who underwent esophagogastroduodenoscopy within the past one year and compared them against cases from the year 1993 and 2008. Materials and Methods: All patients diagnosed with nonvariceal upper gastrointestinal system bleeding who underwent esophagogastroduodenoscopy in the Gastroenterology Clinic of S.B.U. Derince Training and Research Hospital in the last one year were retrospectively reviewed. Demographic data, comorbidities, and esophagogastroduodenoscopy results of 160 patients were analyzed. The results were compared with data from 1993 and 2008. Results: In our patient cohort, the male:female ratio was 2:1 and the mean age was 59.8 years. The most common cause of bleeding was gastritis, followed by peptic ulcers. Ulcers were most commonly seen in the bulbus region. The presence of active bleeding was more common in bulbus ulcers compared to the antrum. The mean age and the proportion of women in our patient cohort were higher than in the 1993 and 2008 data. Additionally, duodenal and gastric ulcers were significantly reduced, while gastritis increased in patients from the last year as compared with those in 1993 and 2008. Conclusion: Nonvariceal upper gastrointestinal bleeding is more common in males and in older patients. The mean age of the patients increased and the frequency of ulcers decreased owing to the increase in life expectancy and success of Helicobacter pylori treatment over the past 25 years. Due to current treatment approaches, mortality rates associated with gastrointestinal system bleeding can be reduced.

Keywords: Gastrointestinal system bleeding, endoscopy, nonvariceal bleeding

ve son 25 yllda üst Gís kanamalı hastaların özelliklerindeki değişimi değerlendirmeyi amaçladık

\section{GEREÇ ve YÖNTEM}

Gastroenteroloji Kliniği'nde son 1 yılda varis dişı üst GIS kanaması ön tanısıyla endoskopi uygulanan hastalar retrospektif olarak değerlendirildi. Saptanan 160 hastanın yaş, cinsiyet, ek hastalık durumu, ilaç kullanımı, ÖGD bulguları ve tekrar kanama olup olmadığı hastane kayıtları incelenerek tespit edildi. Elde edilen veriler SPSS 22 istatistik paket programı aracılığıyla tanımlayıcı istatistikler kullanılarak analiz edildi. Sonuçlar, yine aynı bölgede derlenen 1993 ve 2008 verileri ile verileri ile karşılaştırıldı. Ki-kare testi kullanılarak p <0.05 anlamlı kabul edildi. 


\section{BULGULAR}

Son 1 yılda toplam 160 hastaya varis dışı üst GíS kanama ön tanısıyla gastroskopi yapıldı. Bu hastaların 107'si (\%66.9) erkek 53’ü (\%33.1) kadındır. E:K oranı 2:1 olarak saptanmıştır. 18 ile 90 yaş aralığında değişen yaşlarda olan hastalarda ortanca yaş 64 olarak bulunmuştur. Toplam 41(\%25.6) kişide bir komorbid hastalık olup, 29 (\%18) hastada antiagregan, antikoagülan ya da nonsteroid antiinflamatuvar ilaç (NSAID) kullanımı saptanmıştır. Incelenen 160 hastanın 18'inde (\%11.3) normal üst GİS endoskopi bulguları saptanmıştır. Toplam 59 hastada ülser (\%36.9), 46 hastada yüzeyel gastrit (\%28.8), 18 hastada eroziv gastrit (\%11.3), 13 hastada kitle (\%8.1) ve 6 hastada da midede polip ve Mallory-Weiss yırtığ 1 saptanmıştır (Tablo 1). Ülser saptanan hastalarda en sık lokalizasyon (n: 37, \%62.7) bulbus olarak bulunmuştur. Bulbustan sonra en sik antrum (n: 11, \%18.6), ardından 5 vakada korpus veya kardiya, 3'er vakada da özofagus ve post bulber duodenum gelmektedir (Tablo 2). Ülserler Forrest sinıflama-

Tablo 1. Üst GISS kanama nedeniyle yapılan endoskopilerde saptanan lezyonlar

\begin{tabular}{lc} 
Neden & $\mathbf{n = 1 6 0}$ \\
Ülser & $\% 36.9$ \\
Yüzeyel gastrit & $\% 28.8$ \\
Eroziv gastrit & $\% 11.3$ \\
Kitle & $\% 8.1$ \\
Polip & $\% 1.9$ \\
Mallory-Weiss & $\% 1.9$ \\
Normal gastroskopi & $\% 11.3$ \\
\hline
\end{tabular}

Tablo 2. Ülser saptanan hastalarda lezyonun lokalizasyonu

\begin{tabular}{lc}
\hline Lokalizasyon & n=59 \\
Bulbus & $\% 62.7$ \\
Antrum & $\% 18.6$ \\
Korpus-Kardiya & $\% 8.5$ \\
Özofagus & $\% 5.0$ \\
Post-bulber & $\% 5.0$
\end{tabular}

sına göre değerlendirildiğinde antrum ülserlerinin l'i Forrest-1 (\%9), l'i Forrest-2 (\%9) geri kalan 9'u Forrest-3 (\%82) olarak saptanırken, bulbus ülserlerinin 6'sı Forrest-1 (\%16), 12 'si Forrest-2 (\%32) ve geri kalan 19'u ise Forrest-3 (\%52) olarak saptanmıştır. Tümör saptanan 13 hastanın 4'ünde tümör antrum yerleşimli, 8'inde ise korpus veya kardiya yerleşimlidir. 1 hastada ise opere mide anastomoz hattında tümör saptanmıştır. Eroziv gastrit saptanan hastaların \%50'sinde (n: 9) yalnızca antrum tutulmuşken yüzeyel gastrit görülen hastaların \%58'inde (n: 27) tüm mide mukozasının tutulduğu görülmüştür. Toplamda 2 (\%1.25) vakada yeniden kanama görülmüş olup bu vakalar Forrest-1B bulbus ülseri ve yüzeyel pangastrit saptanan hastalar olmuştur.

1993 yılında hastaların yaş ortalaması 47.5, E:K oranı 3:1, 2008 yılında yaş ortalaması 57.3 , E:K oranı 2.4:1 bizim çalışmamızda da yaş ortalaması 59.8, E:K oranı 2:1 olarak saptanmıştır. 1993 yılında varis kanamalar dışlandığında hastaların \%60'ında duodenal ülser, \%19.l'inde gastrik ülser, \%17.3'ünde gastrit saptanmış, ülserli vakaların \%35.9'unda Forrest 1-2 lezyon saptanmıştır. 2008 yllında varis kanamalar dışlandığında hastaların \%42.2'sinde duodenal ülser, \%21.7'sinde gastrik ülser, \%18.3'ünde gastrit saptanmış, ülserli vakaların \%59.2'sinde Forrest 1-2 lezyon saptanmıştır. 2018 verilerinde ise hastaların \%25'inde duodenal ülser, \%10'unda gastrik ülser, \%40'ında gastrit saptanmış, ülserli vakaların \%41.7'sinde Forrest 1-2 lezyon saptanmıştır. 2018 verilerinde hem 2008 hem de 1993'e göre duodenal ülser ve gastrik ülser sıklığı anlamlı ölçüde azalırken gastrit sıklığı anlamlı ölçüde artmıştır (Tablo 3).

\section{TARTIŞMA}

Üst GIS kanaması; özofagus, mide ve duodenum proksimalini kapsayan Treitz ligamanından daha üst seviyelerdeki kanamalar olarak tanımlanmaktadır (4). En sık neden olarak peptik ülser gösterilmekte olup neredeyse tamamı mide antrumu ve duodenum bulbusunda görülmektedir. Peptik ülser için en önemli iki risk faktörü, NSAID kullanımı ve Helicobacter pylori varlığıdır (5). Diğer sık görülen nedenlerden gastrit, özofajit ve duodenit de yine aynı risk faktörlerine bağlı olup ülsere göre daha hafif formlar olarak değerlendirilebilir (6). NSAID ajanlar prostaglandin inhibisyonuna bağlı gastrik mukoza üzerinde lokal ve sistemik etkiyle mukozal hasarlanmayı arttırarak inflamasyonla başlayan ve ülserasyona giden seyri

Tablo 3. Varis dışı üst GİS kanama nedeniyle yapılan ÖGD bulgularının yıllara göre dağılımı*

$\begin{array}{lcccc} & \mathbf{1 9 9 3}(\mathbf{n : ~ 1 1 0 )} & \mathbf{2 0 0 8}(\mathbf{n : ~ 2 3 0 )} & \mathbf{2 0 1 8}(\mathbf{n : ~ 1 6 0 )} & \text { p değeri } \\ \text { Duodenal ülser } & \% 60 & \% 42.2 & \% 25 & \mathrm{p}<0.05 \\ \text { Gastrik ülser } & \% 19.1 & \% 21.7 & \% 10 & \mathrm{p}<0.05 \\ \text { Gastrit } & \% 17.3 & \% 18.3 & \% 40 & \mathrm{p}<0.05\end{array}$

*1993 ve 2008 verileri ilgili çalışmadaki verilerden varis kanamaları çıkarılarak yeniden hesaplanmıştır. 
hızlandırmaktadır (7). İflamasyona bağlı kanama nedenleri dışında; özofagus varisleri, anjiyodisplaziler, Dieulafoy's lezyonu, gastrik antral vasküler ektaziler (GAVE) gibi vasküler nedenler de kanamaya yola açabilmektedir (8).

Çalışmamızdaki hastalar minimum 18 maksimum 90 yaşında olup ortalama yaş 59.8( \pm 18.5$)$ saptanmış, hastaların \%69.4’ü 50 yaş üstü, \%46.2'si ise 65 yaş üstü olarak saptanmıştır. Hastaların 2/3’ü ( $\mathrm{n}=107, \% 66.9)$ erkek cinsiyettedir. 1993 yllında 47.5, 2008'de 57.3 olan yaş ortalamasının 2018'de 59.8'e yükseldiği görülmüştür. Yine 1993'te 3:1, 2008'de 2.4:1 olan Erkek/Kadın oranı 2018 verilerine göre 2:1'e düşmüştür (9). Son 25 yılda GIS kanamalı hastaların yaş ortalamasının artmasi; toplumda ortalama yaşam süresinin artmasına ve medikal tedavilere ulaşımın kolaylaşmasıyla genç hastaların erken dönemde dispeptik yakınmalarla tedavi olabilmesine bağlanmaktadır. Halen erkek hastalar ağırlıkta olsa da yıllar içerisinde kadın hastaların oranının arttı̆̆ göze çarpmakta olup bu durumu değişen toplum yapısıyla birlikte kadınların çalışma hayatı stresine, düzensiz beslenme ve stres faktörlerine daha fazla maruz kalması şeklinde speküle edebiliriz. Ayrıca yine kadınların toplumsal hayattaki öneminin artmasıyla orantılı olarak eskiye nazaran hastaneye daha kolay ulaşabilmeleri de bu oranın artmasında etkili olabilir.

Hastaların 1/4'ü beraberinde bir komorbid hastalığa sahip $(\mathrm{n}=41, \% 25.6)$ ve $1 / 5$ ' $\mathrm{de}$ anti-agregan $(\mathrm{n}=8, \% 5)$, anti-koagülan ( $\mathrm{n}=6, \% 3.8$ ) ya da NSAID (ASA, $n=10, \% 6.3$, diğer NSAID n=5, \%3.1) ilaçlar kullanmaktadır. Literatür verilerinde komorbid hastalık ve ilaç kullanımı, özellikle de NSAID kullanımı daha sık saptanmakla birlikte bizim çalısmamızda düşük seviyelerde bulunması araştırmacılar tarafından değerlendirilmiş ve çalışmanın retrospektif dizaynına bağlı veri yetersizliği nedeniyle olabileceği düşünülmüştür (10).

Bizim çalışmamızda literatürden farklı olarak en sık gastrit varlığı saptanmış olup toplam 64 (\%40) hastada görülmüştür. 1993'te \%17.3, 2008'de \%18.3 olan gastrit sıklığının 2018'de anlamlı ölçüde arttı̆̆ı görülmüştür. Eroziv gastrit de bir kanama nedeni olup özellikle hastanın endoskopiye alınma zamanının uzamasının bu tür tanıları arttırdığı düşünülmektedir. Ayrıca Dieulafoy lezyonu görülmemesi de yine endoskopinin aktif dönemde yapılamamasına bağlı olabilir. Peptik ülser ise gastriti takiben ikinci sırada saptanmıştır. Ülser vakaları arasında en sık bulbus lokalizasyonunda saptanmıştır ( $\mathrm{n}=37$, \%62.7). Telaku ve arkadaşlarının yaptığı 460 vakalık bir çalışmada da en sık kanama lokalizasyonu \%64.8 oranında duodenum olarak bulunmuş olup çalışmamızla uyumlu gö- rülmüştür (11). Duodenal ülser kanamaları fazlalığının Türk toplumundaki Helicobacter pylori enfeksiyonu sıklığı ile de ilişkili olabileceği de düşünülmüştür (12). Değerlendirilen hastalar içerisinde 2 hasta tekrar kanama ile hastanemize başvurmuş, üst GIS kanama nedenli ölüm saptanmamıştır.

Literatürde yapılan çalışmalarda üst GIS kanama insidansında, kanama nedenleri ve lokalizasyonlarında ciddi değişmeler olduğu gösterilmiştir (13). Duodenal ülser sıklığı 1993'ten 2008'e kadar anlamlı oranda düşmüş, bizim verilerimizde de hem 10 yll hem de 25 yll öncesine göre anlamlı ölçüde düşük bulunmuştur. 1993 ve 2008 arasında fark bulunmayan gastrik ülser sıklığı da yine bizim verilerimize göre hem 1993 hem de 2008'e göre anlamlı ölçüde azalmıştır (14). Ülser kanamalarında, özellikle de duodenal ülserlerde görülen bu azalma, zaman içerisinde artan Helicobacter pylori eradikasyon başarısına bağlanmaktadır.

Tedavide intravenöz sıvı tedavisi, asit baskılayıcı ajanlar ve hemodinami kontrolü sağlanamayan $(\mathrm{Hb}<8 \mathrm{~g} / \mathrm{dl})$ hastalarda eritrosit replasmanı önerilmekte olup uygun hastalarda endoskopik müdahaleler uygulanmaktadır $(15,16)$. Antiplatelet ilaç kullanan hastalarda trombosit replasmanının ek fayda sağlamadığı daha önce yapılan çalışmalarda gösterilmiştir (17). Hastalarda yatarak tedavi sirasinda intravenöz proton pompa inhibitörü (PPI) tedavisi verilmekte, taburculuk sonrası takiplerinde oral tedavilere devam edilmektedir. PPI kullanımının rekürren kanama riskini düşürdügü ve oral/intravenöz kullanım arasında fark olmadığı gösterilmiştir (18-20).

Kliniğimizdeki 1 yıllık üst GiS kanama başvuruları geriye doğru tarandığında özellikle erkek ve ileri yaş hasta grubundaki yoğunluk dikkati çekmektedir. Ülkemizde son 25 yılda üst GIS kanamalı hastaların yaş ortalamasındaki artış göze çarpmaktadır. Uzayan yaşam süresi ve çoklu ilaç kullanımı bu konudaki en önemli etkenlerdir. Yine ülkemizdeki Helicobacter pylori enfeksiyonu sıklı̆ına bağlı duodenal ülserlerdeki fazlalık da dikkati çekmektedir. Ancak yıllar içerisinde eradikasyon başarısındaki artış son 25 yılda duodenal ülser sıklığını önemli ölçüde azaltmıştır. Kliniğimizde tedavi ve takip edilen hastalarda yeniden kanama oranının düşük olması ve mortalite saptanmaması kılavuz önerilerine uygun olarak yapılan tedavilerin başarısı ve uzun dönem takipte PPI kulanımının etkisi olarak değerlendirilebilir. Retrospektif yapılan bu çalışma, Türk toplumundaki üst GIS kanamaların karakteristik özelliklerine yönelik bir fikir vermekte ve son 25 yıldaki değişikliklere ışık tutmaktadır. Bununla birlikte prospektif olarak dizayn edilmiş ve daha çok sayıda hastanın dahil olacağı ileri çalışmalara ihtiyaç vardır.

\section{KAYNAKLAR}

1. Colle I, Wilmer A, Le Moine O, Debruyne R, Delwaide J, Dhondt E, et al. Upper gastrointestinal tract bleeding management: Belgian guidelines for adults and children. Acta Gastroenterol Belg 2011;74:45-66.

2. Gralnek IM, Barkun AN, Bardou M. Management of acute bleeding from a peptic ulcer. N Engl J Med 2008;359:928-37. 
3. Cook DJ, Guyatt GH, Salena BJ, Laine LA. Endoscopic therapy for acute nonvariceal upper gastrointestinal hemorrhage: a meta-analysis. Gastroenterology 1992;102:139-48.

4. Biecker E. Diagnosis and therapy of non-variceal upper gastrointestinal bleeding. World J Gastrointest Pharmacol Ther2015;6:172-82.

5. Kao CY, Sheu BS, Wu JJ. Helicobacter pylori infection: An overview of bacterial virulence factors and pathogenesis. Biomed J 2016;39:14-23.

6. Pang SH, Leung WK, Graham DY. Ulcers and gastritis. Endoscopy 2008;40:136-9

7. Matsui H, Shimokawa O, Kaneko T, Nagano Y, Rai K, Hyodo I. The pathophysiology of non-steroidal anti-inflammatory drug (NSAID)-induced mucosal injuries in stomach and small intestine. J Clin Biochem Nutr 2011;48:107-11.

8. Samuel R, Bilal M, Tayyem O, Guturu P. Evaluation and management of Non-variceal upper gastrointestinal bleeding. Dis Mon 2018;64:333-43.

9. Sezikli M, Tiftikçi A, Çetinkaya ZA, et al. Son 15 yılda akut üst gastrointestinal sistem kanaması olan hastaların endoskopik bulgularında ne değişti? Akademik Gastroenteroloji Dergisi 2008;7:152-5.

10. Laine L. Approaches to nonsteroidal anti-inflammatory drug use in the high-risk patient. Gastroenterology 2001;120:594-606.

11. Telaku S, Kraja B, Qirjako G, Prifti S, Fejza H. Clinical outcomes of nonvariceal upper gastrointestinal bleeding in Kosova. Turk J Gastroenterol 2014;25(Suppl 1):110-5.

12. Bayindir Bilman F, Ozdemir M, Baysal B, Guzel Kurtoglu M. Prevalence of $\mathrm{H}$. pylori in gastric biopsy specimen in the southeastern region of Turkey. J Infect Dev Ctries 2016;10:1177-82.
13. Loperfido S, Baldo V, Piovesana E, Bellina L, Rossi K, Groppo M, et al. Changing trends in acute upper-GI bleeding: a population-based study. Gastrointest Endosc 2009;70:212-24.

14. Akkan Çetinkaya Z, Sezikli M, Bünül F, Şirin G. A revision of patients who underwent gastroscopy because of non-variceal upper gastrointestinal bleeding in the last year. Kocaeli Med J 2013;2:11-4.

15. Sung JJ, Chiu PC, Chan FKL, Lau JY, Goh KL, Ho LH, et al. Asia-Pacific working group consensus on non-variceal upper gastrointestinal bleeding: an update 2018. Gut 2018;67:1757-1768. Epub 2018 Apr 24.

16. Blair SD, Janvrin SB, McCollum CN, Greenhalgh RM. Effect of early blood transfusion on gastrointestinal haemorrhage. Br J Surg 1986;73:7835 .

17. Zakko L, Rustagi T, Douglas M, Laine L. No benefit from platelet transfusion for gastrointestinal bleeding in patients taking antiplatelet agents. Clin Gastroenterol Hepatol 2017;15:46-52.

18. Yen HH, Yang CW, Su WW, Soon MS, Wu SS, Lin HJ. Oral versus intravenous proton pump inhibitors in preventing re-bleeding for patients with peptic ulcer bleeding after successful endoscopic therapy. BMC Gastroenterol 2012;12:66.

19. Khuroo MS, Yattoo GN, Javid G, Khan BA, Shah AA, Gulzar GM, et al. A comparison of omeprazole and placebo for bleeding peptic ulcer. N Engl J Med 1997;336:1054-8.

20. Javid G, Masoodi I, Zargar SA, Khan BA, Yatoo GN, Shah AH, et al. Omeprazole as adjuvant therapy to endoscopic combination injection sclerotherapy for treating bleeding peptic ulcer. Am J Med 2001;111:2804. 